Mit den von J. $\operatorname{Tra}_{\mathrm{a}} \mathrm{e}^{1}$ ) auf rein physikalischem Wege erhaltenen Resultaten stimmen die so auf chemischem Wege gefundenen Ergebnisse Stobbe's überein. Aus den Änderungen des molekularen Lösungsvermögens von in Methyl-, respektive Äthylalkohol gelöstem Azetessigester zieht Traube den Schluss, dass sich in diesen Lösungsmitteln mehr Enol bildet als im freien Ester vorhanden ist. $\mathrm{Brühl}{ }^{2}$ ) dagegen schliesst aus dem Ergebnis optischer Analysen, dass die Zusammensetzung des Azetessigesters dieselbe sei in reinem und in gelöstem Zustande bei Verwendung von Chloroform, Wasser und Methylalkohol als Lösungsmittel, also die reine Ketoform darstellt.

Vielleicht gelingt es den von S to b b e in Aussicht gestellten weiteren Untersuchungen diesen Widerspruch aufzuklären.

\title{
Zur Molekulargewichtsbestimmung auf kryoskopischem Wege
} bei sehr niedriger Temperatur haben H. Stobbe und E. Müller ${ }^{3}$ ) als Lösungsmittel Chloroform verwendet.

Da bei derartigen Versuchen die genaue Einhaltung einer konstanten Temperatur Schwierigkeiten bietet, so ist es von Interesse, die Versuchsanordnung der genannten Autoren kennen zu lernen.

Der von E. Beckmann ${ }^{\mathbf{4}}$ ) zur Kühlung mit flüssiger Luft beschriebene Gefrierapparat wurde etwas modifiziert. Als Kühlgefäss diente ein in Watte gepacktes Weinhold'sches Gefäss, das mit einem Gemisch von fester Kohlensäure und viel Äther beschickt wurde. Die Temperatur der Kühlflussigkeit betrug bis zu $-79^{\circ}$. Das Gefrierrohr ${ }^{5}$ ) wich dadurch von der üblichen Anordnung $a b$, dass es von einem angeschmolzenen and auf $400 \mathrm{~mm}$ Quecksilberdruck evakuierten Hohlmantel umgeben war. Die gewählte Luftverdünnung ermöglicht den günstigsten Temperaturaustausch und hat sich im vorliegenden Fall sehr bewährt. Stärkere Luftverdünnung setzt das Wärmeleitungsvermögen zu sehr herab, eine geringere Evakuierung aber hat eine zu rasche Abkühlung des Lösungsmittels zur Folge.

Als geeignetes Lösungsmittel erwies sich das Chloroform Anschü tz ${ }^{6}$ ) (Salizylid-Chloroform). Mit den sonst noch verwendeten, auf dem üblichen

1) Ber. d. deutsch. chem. Gesellsch. zu Berlin 29, 1715.

2) Zeitschrift f. physikal. Chemie 51, 519 .

3) Annalen d. Chemie $\mathbf{3 5 2}, 147$.

4) Zeitschrift f. physikal. Chemie 44, 184; diese Zeitschrift 43, 515; siehe auch diese Zeitschrift 43, 39 und 239.

5) Angefertigt von F. O. R. Götze in Leipzig.

6) D. R. P. 70615; dirse Zeitschrift 32, 605. 
Wege gereinigten Chloroformsorten des Handels wurden keine guten Erfahrungen gemacht.

Um die Feuchtigkeit der Luft auszuschliessen, warde zur Bewegung der völlig von der Luft abgeschlossenen Chloróformlösung der von E. Beckmann ${ }^{1}$ ) angegebene, elektru-magnetische Rührer verwendet, der sich sehr bewährte. Die Einführung des zu lösenden Körpers im vorliegenden Fall Azetessigester - geschah mit einer 0 stwa $1 d$ 'schen ipette.

Zur Bestimmung der molekularen Gefrierpunktserniedrigung des Chloroforms wurden Versuche mit Benzoësäureäthylester angestellt. Die Konstante für gefrierendes Chloroform ist auffallend hoch, und zwar $=499$.

Die beschriebene MeFig. 22. thode wurde zur Bestimmung des Molekulargewichts von Azetessigester benutzt; es ergab sich, dass der Ester in gefrierendem Chloroform, wie auch sonst, monomolekular ist, was für die im vorigen Artikel besprochenen Untersuchungen Stobbe's über den Azetessigester von wesentlichem Interesse war. Eine andere Modifikation des Beckmann'schen Gefrierapparates bringt J. Mc. C. Sand ers ${ }^{2}$ ) in Vorschlag. In den Boden der Gefrierröhre ist, wie aus Figur 22 ersichtlich, seitlich eine doppelt gebogene Kapillarröhre $A$ eingeschmolzen, an der ein dünner Gummischlauch mit einem kleinen

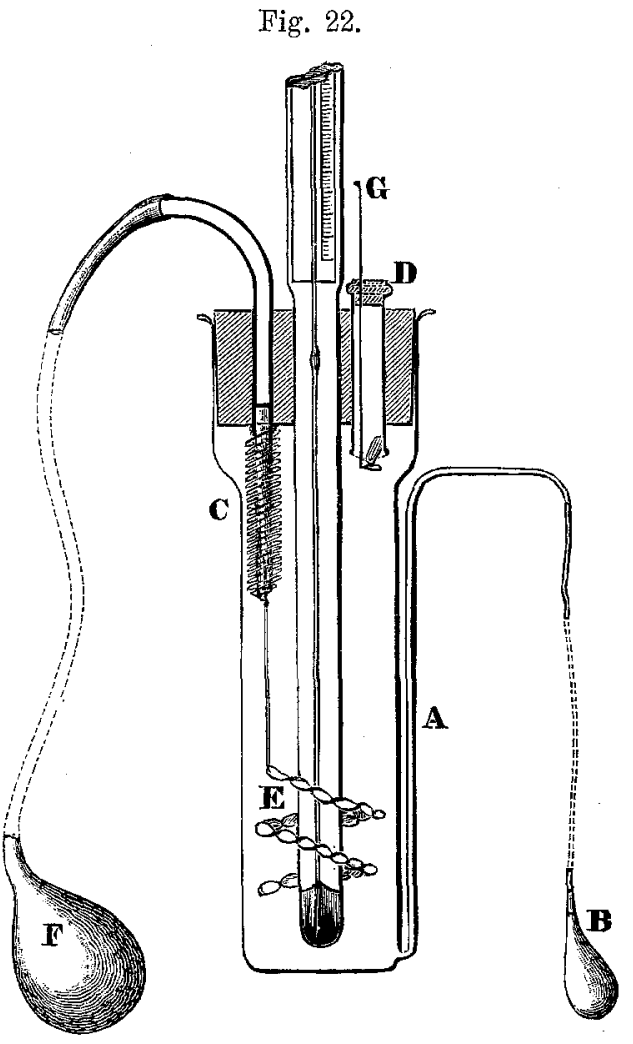

1) Zeitschrift f. physikal. Chemie 44, 169; diese Zeitschrift 43, 511.

2) Proceedings of the chemical society $22,165$. 
Gummiball B befestigt ist. Die Gefrierröhre sitzt derart in dem Aussenmantel, dass dessen Wandung die Kapillare A berührt. Die Flüssigkeit in A wird durch Zusammendrücken des Gummiballes B zuerst vollständig entfernt. Dann wird der Gummischlauch zusammengedrückt und gleichzeitig seine Verbindung mit dem Gummiball gelöst. Sobald dieser sich wieder mit Luft gefüllt hat, stellt man die Verbindung wieder her ; hierbei steigt eine kleine Menge des Lösungsmittels in die Kapillare A. Da sie der Kältequelle am nächsten ist, gefriert hier die Lösung zuẹst; im gewünschten Augenblick kann durch einen scharfen Druck auf den Ball B eine Anzahl Kristalle in das eigentliche Gefrierrohr getrieben werden, welche die Kristallisation einleiten.

Ein pneumatischer Rührer E, der im oberen Teil C aus Aluminium, zum Teil auch aus Glas, sonst aber aus Platin gefertigt ist, wird mit Hilfe des Gummiballs F bedient.

Eine kleine, senkrechte Röhre D führt durch eine dritte Bohrung bes Gummistopfens - in der ersten Bohrung sitzt das BeckmannThermometer, in der zweiten der Rührer - und vertritt die Stelle des seitlichen Ansatzrohrs bei Beckmann; sie dient zur Einführung der Substanz. Die Gefrierröhre kann aus einem kleinen Soxleth'schen Extraktionsapparat durch Umbiegen des seitlichen Heberrohrs hergestellt werden.

Die beschriebene Einrichtung soll es ermöglichen, dass bei den Parallelversuchen mit dem Lösungsmittel und mit der Lösung eine möglichst gleichmälsige Überkühlung erzielt wird. Sie vermeidet die Schwierigkeiten, die das Zugeben von Eiskristallen zur Einleitung des Gefrierens ${ }^{1}$ ) bei dem eigentlichen Beckmann-Apparat bietet.

Die Bedingungen, unter denen Metallsulfide niedergeschlagen und aufgelöst werden, haben vor kurzem G. Bruni und M. Padoa ${ }^{2}$ ) experimentell untersucht; sie zeigten, dass durch die Behandlung mit Schwefelwasserstoff unter Druck Metallsulfide auch aus solchen Lösungen gefällt werden, die unter Atmosphärendruck keinen Niederschlag geben, während andēerseits die Fällung von Metallsulfiden, die unter gewöhnlichen Umständen von Schwefelwasserstoff niedergeschlagen werden, verhindert wird.

1) Vergl. hierzu diese Zeitschrift $\mathbf{4 8}, 514$.

2) Rend. R. Acc. dei Line. (5) 14, 2. Sem. 525 (1905); diese Zeitschrift 45, 621 . 